\title{
THE "BLIND SPOT" OF PLAGIARISM: A STUDY ON PLAGIARISM IN THE ARTICLES SUBMITTED TO BIRAT JOURNAL OF HEALTH SCIENCES
}

\author{
Chhetri $P^{1^{*}}$, Rimal $H S^{2}$, Kafle $S U^{3}$, Kafle $T K^{4}$
}

\begin{abstract}
Affiliation
1. Managing Editor, Birat Journal of Health Sciences, Birat Medical College and Teaching Hospital

2. Professor, Department of Paediatrics, Birat Medical College and Teaching Hospital

3. Associate Professor, Department of Pathology Medicine, Birat Medical College and Teaching Hospital

4. Lecturer, Department of Community Medicine, Birat Medical College and Teaching Hospital
\end{abstract}

\section{ARTICLE INFO}

Received : 02 February, 2020
Accepted : 04 April, 2020
Published : 30 June, 2020

(c) Authors retain copyright and grant the journal right of first publication with the work simultaneously licensed under Creative Commons Attribution License CC - BY 4.0 that allows others to share the work with an acknowledgment of the work's authorship and initial publication in this journal.

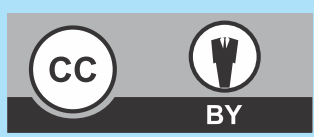

ORA 163

DOI: https://doi.org/10.3126/bjhs.v5i1.29632

* Corresponding Author

Mr. Prabin Chhetri

Managing Editor

Birat Journal of Health Sciences (BJHS)

Birat Medical College Teaching Hospital

Email:praveenchhetri@gmail.com

ORCID ID: https://orcid.org/0000-0002-5259-1119

\section{Citation}

Chhetri P, Rimal HS, Kafle SU, Kafle TK. The "Blind Spot" of Plagiarism: A Study on Plagiarism in The Articles Submitted to Birat Journal of Health Sciences. BJHS 2020;5(1)11: 950-954.

\section{ABSTRACT}

\section{Introduction}

The word plagiarism, in literature, means stealing someone's works without acknowledging the author. It is an unavoidable fact that an article has to be original when it is presented for publication. Often it is seen that during the research works, authors put lot of effort in collecting the facts and figures for their article but they seem to have a blind spot when it comes to plagiarism. The detection of the plagiarism is a challenging and time consuming task for most of the journals.

\section{Objectives}

The objective of the study is to understand the level of plagiarism in the articles submitted in Birat Journal of Health Sciences.

\section{Methodology}

A descriptive cross-sectional study was conducted on plagiarism by retrieving the data of articles submitted to Birat Journal of Health Sciences (BJHS), an official medical journal of Birat Medical College (BMC), from April 2017 to August 2018. Total 111 articles were examined through the iThenticate Software, a commercial Plagiarism Detection Tool (PDT) Version 2.0.8. Articles were analyzed using descriptive statistics.

\section{Result}

It was found that $63(56.75 \%)$ articles were found to be less than $20 \%$ plagiarized and $48(43.22 \%)$ articles were found above the cut-off point ( $20 \%$ plagiarized) putting them in the category of plagiarized article.

\section{Conclusion}

It was found that the incidence of plagiarism in the articles submitted to BJHS was very common. It is also evident from the study that a commercial plagiarism detection tool (PDT) can be a very useful tool for detecting and preventing plagiarism in the articles. It was also noticeable to find that the articles of clinical consultants(who are not associated with academic institutions) had higher level of plagiarism in their articles in comparison to the academicians (who are associated with academic institutions).

\section{KEYWORDS}

Medicine, iThenticate, plagiarism, publishing. 


\section{INTRODUCTION}

Research articles are the integral part in any field of study where the novel ideas, experiments and any new or peculiar case studies are published. Further in medical studies, it plays an immaculate role as the dissemination of information with these articles are so powerful that the work of the author gets transcended to many others which in turn acts as a base for further research process. This continuum goes along and many more benefit from them. Thus, every article that is to be published has to be original and innovative in its own. BJHS is the official journal of Birat Medical College and Teaching Hospital (BMCTH), Biratnagar, Nepal.

According to Oxford Dictionary, "the word plagiarism was originated in $17^{\text {th }}$ century from the Latin word plagium which basically means a kidnapping. ${ }^{1}$ In literary terms, plagiarism refers to a practice of taking somebody else's work or ideas and presenting them of one's own. It is the illegal copying of the texts, phrases and sentences without taking consent from the authors or without citing them and claiming them to be your own. In academic fraternity, plagiarism is a serious offense, often regarded as an intellectual theft. Plagiarism is a case of concern for every journal and is the most general issue that the journals face at the current time. It not only devalues the originality of the article, rather it creates injustice for the readers of the article who read it as one original article whereas, in fact, it is not. When an article is submitted to the journal, it has to be original and free of plagiarism. Every journal have their own cut-off limits for the plagiarism and based on that, they accept, reject, retract or return the articles to reduce the level of plagiarism in these articles.

The cases of plagiarism are widely studied and several articles can be found in the western literatures regarding plagiarism from the very beginning. ${ }^{2-4}$ Unfortunately there are very few literatures found in the Asian perspective, however in an Indian setting, there are few articles available with regard to plagiarism. ${ }^{5}$ In the context of Nepalese literature, sufficient scientific study in this field is still lacking. There are few editorials and newspaper articles available regarding plagiarism and very limited articles are available with small coverage but are scientifically poor. So, the current article tries to highlight the status of plagiarism in articles submitted to BJHS.

\section{METHODOLOGY}

A descriptive cross-sectional study was carried out by reviewing the plagiarism record of all articles that were submitted to BJHS from April 2017 to August 2018. The articles submitted were then uploaded in the iThenicate plagiarism software (version 2.0.8) and the plagiarism was detected. The iThenticate is world-renowned software for plagiarism detection tool, trusted and used by several publication houses across the world. For the better results of plagiarism, the options in the iThenitate were set to "excluding quotes, bibliography, small matches up to six words and small sources up to $1 \%$ ", these were done to avoid the unintentional plagiarism in the articles. ${ }^{6}$
In this study, 111 articles were analyzed for plagiarism which included editorials, original articles, case reports, and viewpoints. The articles were added up as they were submitted to BJHS. The benchmark for plagiarism for an article to be accepted in BJHS is less than $20 \%$ so the same $20 \%$ mark was made cut-off limit for plagiarism standard in this research as well. Thus any article that has the plagiarism of $20 \%$ or more was considered as a plagiarized article in the current study.

\section{RESULTS}

Of the total 111 articles that were tested against the plagiarism detection software (i.e., iThenicate plagiarism software version 2.0 .8$), 48(43.24 \%)$ articles were found to be plagiarized where as $63(56.75 \%)$ were within the set standards, i.e., below the $20 \%$ cut-off.(Figure 1).

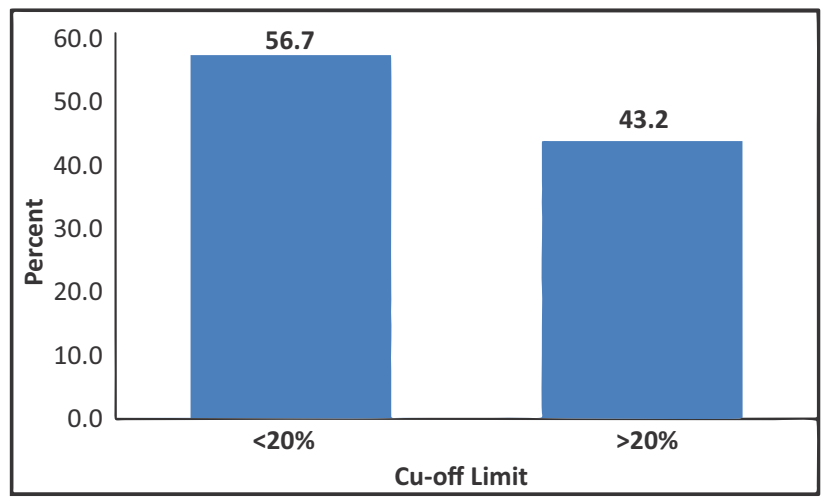

Figure 1: Percentage distribution of plagiarized and nonplagiarized articles

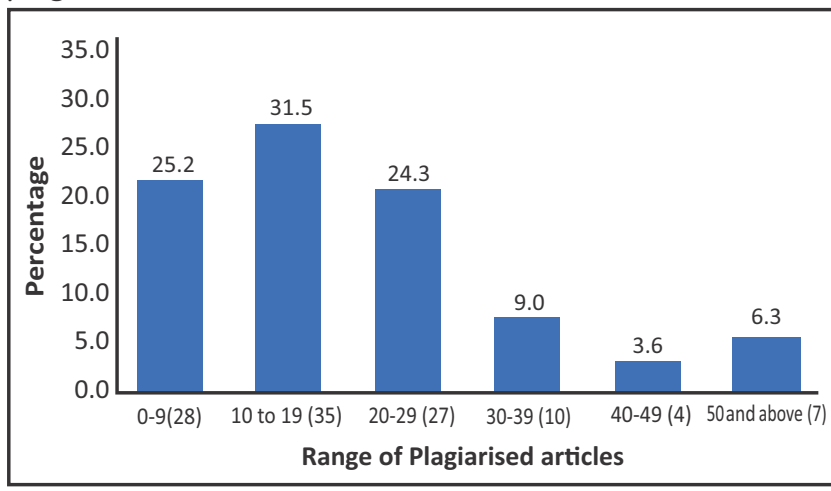

Figure 2: Distribution of Plagiarism Pattern (N-111)

The above figure shows that out of the 111 articles subjected for plagiarism, 35 articles (31.5\%) were within the range of $10-19 \%$ level of plagiarism where as7 articles (6.3\%) were found as above the $50 \%$ level of plagiarism

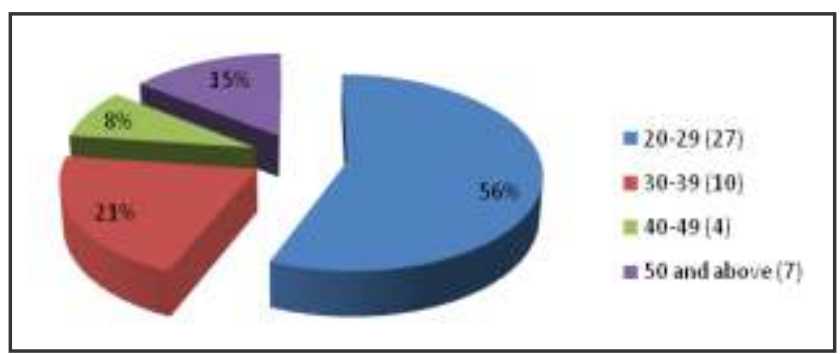

Figure 3: Percentage distribution of plagiarized article 
The above figure shows the percentage distribution of plagiarism within the plagiarized articles. It shows that the majority of the articles (56\%) which were plagiarized were in the range of $20-29 \%$. Interestingly, significant percentage (15\%) of the plagiarized articles had above $50 \%$ plagiarism, which is very serious.

Table1: Descriptive statistics of plagiarism percentage of
study articles
\begin{tabular}{|l|c|}
\hline \multicolumn{1}{|c|}{ Number of total articles } & 111 \\
\hline Mean & 20.03 \\
\hline Standard Deviation & 15.89 \\
\hline Median & 16 \\
\hline Range & $97(0-97)$ \\
\hline
\end{tabular}

Table 2: Mean and Standard deviation of plagiarized
articles by sex
\begin{tabular}{|l|c|c|}
\hline Sex & Mean \pm SD & P value \\
\hline Male & $35.6 \pm 15.8$ & $>0.05$ (Not significant) \\
\hline Female & $35.1 \pm 8.8$ & \\
\hline
\end{tabular}

The above table shows that the mean difference was not significant between the male and female participants in plagiarism.

Table 3: Mean and Standard deviation of plagiarism by
academic profile
\begin{tabular}{|l|c|c|}
\hline Designation & Mean \pm SD & P-value \\
\hline Consultant & $41.1 \pm 22.9$ & \\
\cline { 1 - 2 } MD Resident & $31.7 \pm 3.5$ & \multirow{2}{*}{$<0.001$} \\
\hline Lecturer & $34.9 \pm 10.6$ & \\
\cline { 1 - 2 } Assistant Professor & $33.4 \pm 8.1$ & \\
\cline { 1 - 2 } Associate Professor & $28.3 \pm 5.9$ & \\
\hline Professor & $33.0 \pm 0$ & \\
\hline
\end{tabular}

The mean numbers of plagiarized article were found highest submitted from Consultant clinicians $(41.1 \pm 22.9)$ and this figure is significantly higher than their counterparts. Now thus, it can be concluded that consultant doctors (physicians and surgeons) are found to be significantly associated with plagiarism in their articles in comparison to the faculties ( $p$-value is 0.001).

\section{DISCUSSION}

This cross-sectional study describes the various patterns of plagiarism found in the articles submitted to BJHS. From the various literature studied, it has been found that plagiarism has been a chronic problem globally. The prevalence and pattern of plagiarism has been studied extensively in the western society for many decades. Gilmore et al. found that $42.6 \%$ of research proposals of science, technology, engineering, and mathematics graduate students contained more than the threshold level of plagiarism. ${ }^{2}$ Plagiarism has been a case of concern globally but a recent research has shown that the cases of plagiarism is significant in those countries where English is a secondary language rather than the countries where English is an official language. ${ }^{7}$ It might be applicable in our country too because English is a secondary language in Nepal.

In Southeast Asia, particularly in Nepal and India, the rising crescendo of plagiarism has been noticed. There have been very few researches done in these countries regarding plagiarism as a result of which very limited literatures are available here. The growing trend of plagiarism is because of unawareness of authors, inexperienced researchers; although sometimes people plagiarize deliberately but in many instances, they do so unknowingly because they do not know what is plagiarism and how bad its consequences can be. ${ }^{8}$ In some cases, the articles are being plagiarized to the extent where the authors copy the entire text (introduction, body of the article, discussion, conclusion, figures, and even photograph) from the original article and it seems like the authors copy/paste the entire article only making minor adjustment of their own. ${ }^{6}$

There are often several reasons why people partake in the activities of plagiarism. It might be due to lack of proper knowledge or confusion to properly paraphrase or cite the sources; or there could be various other reasons as well. Students tend to plagiarize the articles more than others during their early stages and the reasons could be many; ranging from lack of research skills, confusion about how to properly cite sources, perception of online information as public knowledge, misconception of intellectual property, copyright, pressure from family, competition for scholarships and jobs, poor time management, organizational skills etc. ${ }^{9}$

We need to understand what factors motivate somebody to plagiarize and why there is an upsurge in the number of authors committing plagiarism. The possible answer could be due to the eagerness of a freshman to publish their article in the early days of their career. This leads to not doing ample of research and merely copying texts from the sources. The easy accessibility of Internet is another factor of committing plagiarism. In BJHS we have found that copy-paste of sentences and phrases are most common in authors that makes articles plagiarized. At this day and age, digital cheating has been one of the key factors of plagiarism. Today, one can reach thousands of sites with a single click of mouse so nobody wants to waste their time in searching books, journals and dissertations, the authors think that the copy- 
paste version in a computer is the best and instant solution to many research related articles. ${ }^{10}$

In most of the developing countries including Nepal, the concept of plagiarism is not prioritized and often not followed strictly. There are several instances when it is seen that even the top-level academicians are caught on the offense of plagiarism. These range from the top-level academicians of Tribhuwan University and several professors of Kathmandu University who were even blacklisted by an International journal. ${ }^{11}$

In many cases, it is found that the researchers have some knowledge about the plagiarism however there is a belief in them that it cannot be successfully avoided. There could be several reasons behind that tendency such as pressure to publish, lack of mentors and funding for research that prompts somebody to plagiarize. ${ }^{12}$

We have noted in our research that there is a vast difference between academicians and clinicians when it comes to the matter of publication and plagiarism (Table 3, p<0.001). Upon our inquiry with the authors, particularly clinicians as to why the levels of plagiarism are high in their articles, the common reply was either they are less concerned about plagiarism or in fact they know so less about it that most often they commit plagiarism more than the threshold level. Authors knowingly, unknowingly or carelessly plagiarize the articles. Also, many journals do not check the plagiarism and the authors have a perception that they would get away with it quite easily. This is a dangerous perception because it not only jeopardizes the career of the author in the long run, but also diminishes the reputation of the journal. Most often, this tendency leads to a duplication of article. In an article entitled "Plagiarism: Who is responsible author or the journal editors?" the author discusses how he had found that $100 \%$ of his original article was copied by another author without his knowledge. ${ }^{13}$ Often these cases go unnoticed as we can see that although the major fault was on the author's side in this case; however, it was also the journal editor's responsibility to undergo plagiarism checking process before sending the article for peer review. The journals often fail to do this.

We had also a similar experience of one article duplication by one of our authors. Of the 48 articles that we found plagiarized, there was one specific article which was found as a duplication of article that had the plagiarism level of a whopping $97 \%$. The author seemed to abrogate all the conventional laws of research writing in this article. The author was tried to be contacted about this but he never responded. Later on while tracking the links of article via the software, we finally found out that, he had sent an almost copy-paste version of a similar article that was previously published by himself changing the heading and some contents in it (a typical case of self-plagiarism).

There are not much strict rules in developing countries including Nepal for these kinds of intentional plagiarism. This gives authors a monopoly and a kind of freedom to conduct such kind of disgraceful acts. In many developed countries, the journals and the academic institutions are too strict in the case of plagiarism. There are several instances where the top-level officials have had several consequences because of their plagiarized contents in the articles. It is interesting to find that even the Vice President of the European parliament and several German cabinet ministers have been fined and even had their doctors degree revoked because of plagiarism. ${ }^{14}$

It is most important to learn about the plagiarism and thereby discover the ways to identify and avoid plagiarism. Many simple steps play a vital role in avoiding plagiarism. There are several simple strategies for avoiding plagiarism such as putting a quotation mark in between the texts and cite the sources for the article or paraphrasing the sentences making sure that one does not reiterate the similar words or phrases. ${ }^{15}$

It is felt that the Universities and the medical colleges should focus more on this issue of plagiarism right from the beginning, i.e. planning of research, to make their students aware about the plagiarism. In medical colleges, efforts have been made by few faculties on individual basis albeit it is not enough. The issues of plagiarism have not been seen seriously across the universities and medical colleges in Nepal. Whereas, it is just opposite in many developed countries. Different universities have taken strict measures regarding plagiarism and making the students aware of it. Several universities have developed a curriculum to their students to create awareness in them with regard to plagiarism. $^{16}$

Looking at the severity of the plagiarism in articles, BJHS has opted to guide the authors on how to minimize the plagiarism in their articles when asked. Also, BJHS in collaboration with $\mathrm{BMC}$ has started giving trainings to the faculties to avoid the plagiarism.

Nowadays, several universities are providing various online links in their websites to deliver a quick and accurate information regarding plagiarism. ${ }^{17}$

In Nepal too, it is the right time that the Medical colleges and the universities should start speaking formally about plagiarism. A separate rubric for plagiarism has to be formulated. They should motivate their students to teach about the consequences of plagiarism in an elaborative manner as after all these students will be the future doctors representing their colleges and universities at the various levels.

In today's world, especially with the evolution of the digital world, there are various plagiarism detection software available where the authors can cross-check their works. Some of these software can be purchased where as there are many free online software/websites that can be used for plagiarism detection. Formal trainings have to be given to authors on the use of such kind of anti-plagiarism software either by the colleges or by professionals so that the authors can understand better about plagiarism and reduce them in their articles.

Likewise, it is the responsibility of the journals to check for 
plagiarism strictly and if possible train the authors about the plagiarism and how can it be avoided. Above all, the authors also should themselves be conscious about it. Rather than copying and pasting the materials bluntly from the sources, authors should do more research in the topic themselves and look for the ways to avoid plagiarism. They might not get noticed or may not get caught in the beginning, but once they step out from these places in an international arena, it is sure that they will eventually get caught there. There are many pragmatic ways to effectively deal with plagiarism, whether these are putting the texts inside a quotation marks and citing them properly or paraphrasing the lines, the authors have to be trained about plagiarism one way or the other.

\section{CONCLUSION}

The above study clearly suggests that plagiarism is often neglected by the authors and is given less importance. Our research study also verifies this fact as of the total 111 articles that were subjected for plagiarism, $43.2 \%$ were found to be plagiarized above our cut-off limit. The high number of authors involved in plagiarism verified in this study is very disconcerting and simultaneously rings an alarming bell to the fact that we need to educate the authors about plagiarism and develop consciousness in them about the severity of plagiarism.

\section{RECOMMENDATIONS}

Though the understanding of plagiarism has been gradually increasing amongst the researchers in Nepal, it is recommended that more trainings and workshops are required to create awareness in this subject. It is also recommended that if the journals could make a track of plagiarized contents in article, it would be beneficial to get the statistics in this area at a national level.

\section{LIMITATIONS OF THE STUDY}

The study was conducted with only the articles that were submitted to BJHS and tested against single plagiarism detection software, i.e., iThenticate Software Version 2.0.8.

\section{ACKNOWLEDGEMENTS}

The author would like to acknowledge all the editorial board members of BJHS who provided their valuable suggestions and insights for the support for this study.

\section{CONFLICT OF INTEREST}

None.

\section{FINANCIAL DISCLOSURE}

None.

\section{REFERENCES}

1. Oxford Online Dictionary. [cited 2019 Nov 16]. Available from: https://www.oxfordlearnersdictionaries.com/definition/english/p lagiarism?q=plagiarism

2. Citation: Peeran SW, Ahmed AM, Mugrabi MH, Peeran SA. Letter to Editor: Simple steps to avoid plagiarism and improve scientific writing. Libyan Journal of Medicine. 2013;8(1).

3. Banerjee I, Roy B, Sathian B, Saha A. Plagiarism: Who is responsible author or the journal editors?. Nepal Journal of Epidemiology. 2013 Sep 30;3(3):277-8.

4. Bretag T. Challenges in addressing plagiarism in education. PLoS medicine. 2013 Dec;10(12).

5. Shamim T. Serious thoughts about plagiarism from India. Saudi journal of anaesthesia. 2012 Jul;6(3):191.

6. Huh S. What happened when Crosscheck was not used for a month in Journal of Neurogastroenterology and Motility?. Journal of neurogastroenterology and motility. $2014 \mathrm{Jul} ; 20(3): 417$.

7. Higgins JR, Lin FC, Evans JP. Plagiarism in submitted manuscripts: incidence, characteristics and optimization of screening-case study in a major specialty medical journal. Research integrity and peer review. 2016 Dec;1(1):13.

8. Kalani V, Twinwal A. Plagiarism and its Consequences. Department of electrical engineering, Indian Institute of Technology Delhi, New Delhi. 2013 Dec 11
9. Why Students Plagiarize [Internet]. Cited 2019 Dec 15. Available from: https://www.mga.edu/plagiarism/why.php

10. Citation: Ma HJ, Wan G, Lu EY. Digital cheating and plagiarism in schools. Theory Into Practice. 2008 Jul 11;47(3):197-203.

11. Citation: Subedi, S. Plagiarism in Nepal: Writing without worries [Internet]. 2017 Jan 6 [cited 2019 Aug 15]. Available from: http:// nepalibytes.com/plagiarism-in-nepal-writing-without-worries/

12. Singh HP, Guram N. Knowledge and attitude of dental professionals of North India toward plagiarism. North American journal of medical sciences. 2014 Jan;6(1):6.

13. Banerjee I, Roy B, Sathian B, Saha A. Plagiarism: Who is responsible author or the journal editors?. Nepal Journal of Epidemiology. 2013 Sep 30;3(3):277-8.

14. Rodriguez V. Plagiarism, its consequences, and how to avoid it. Available from: https://www.eim.uni-paderborn.de/fileadmin/ informatik/Studium/Formalitaeten/Hinweise_zu_Plagiaten/plagiari sm_leaflet.pdf

15. Plagiarism: What It is and How to Recognize and Avoid It [Internet]. Cited 2019 Mar 16]. Available from: https://wts.indiana.edu/writingguides/plagiarism.html

16. Avoiding plagiarism [Internet]. Cited 2019 Apr 21]. Available from: https://web.library.uq.edu.au/research-tools-techniques/ referencing-style-guides/avoiding-plagiarism

17. Referencing [Internet]. Cited 2019 May 22]. Available from: https:// www.wales.ac.uk/en/OnlineLibrary/StudySkills/Referencing.aspx 